\title{
ENERGY EFFICIENCY ASSESSMENT AND IMPROVEMENT MEASURES FOR FURNITURE FACTORY
}

\author{
Dzana Kadric, Nijaz Delalic, Sanda Midzic-Kurtagic, \\ Berina Delalic, Kerima Medar
}
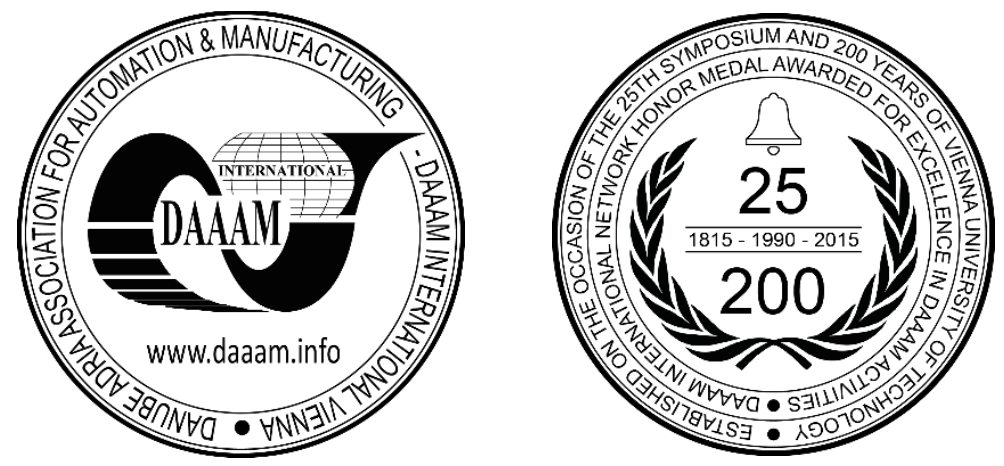

This Publication has to be referred as: Kadric, D[zana]; Delalic, N[ijaz]; Midzic-Kurtagic, S[anda]; Delalic, B[erina] \& Medar, K[erima] (2017). Energy Efficiency Assessment And Improvement Measures For Furniture Factory, Proceedings of the 28th DAAAM International Symposium, pp.0315-0321, B. Katalinic (Ed.), Published by DAAAM International, ISBN 978-3-902734-11-2, ISSN 1726-9679, Vienna, Austria

DOI: $10.2507 / 28$ th.daaam.proceedings.043

\begin{abstract}
Energy consumption of a furniture factory is assessed through detail energy audit which was performed within a framework of the UNIDO National Cleaner Production Program in Bosnia and Herzegovina. Factory consist of three production plants: sawmills and kilns, furniture manufacturing facility and a pellets manufacturing facility. Energy audit was focused on analysing energy consumption of furniture manufacturing facility as well as detection of causes of excessed energy consumption. Following, several energy and resources saving measures are proposed with approximated values of energy and $\mathrm{CO}_{2}$ savings. The paper presents detailed analysis of three improvement measures: replacement of the existing boiler, installation of frequency regulators at the engine of the dirt-blast system and introduction of alternative equipment for cleaning instead of the compressed air. Implementation of these measures will provide significant energy savings of $1.328 .715 \mathrm{kWh} /$ year and $\mathrm{CO}_{2}$ savings of $85,74 \mathrm{t} /$ year.
\end{abstract}

Keywords: energy efficiency; energy audit in industry; furniture factory; energy indicator; energy savings

\section{Introduction}

Share of industry energy consumption in Bosnia and Herzegovina in total energy consumption is approximately 23 $\%$, which is much lower than in countries worldwide [1]. Furthermore, energy intensity of Bosnia and Herzegovina is 0,5 toe/1.000 USD of GDP, which is four times higher than average in the European Union (EU) [2].

Energy efficiency improvement and reduction of energy intensity are important targets for sustainable development worldwide [3]. Industry in Bosnia and Herzegovina, due to its high specific energy consumption and negligible percent of implementation of energy saving technologies offers a high energy saving potential which directly affect an exploitation of energy resources and thus diminishes the negative impact on the environment.

The furniture industry consumes electrical and thermal energy, wood and wood based board material as a basic raw material. Additionally, many auxiliary raw materials such as paints, adhesives, textiles, sponges, etc. are being used. Most of the annual energy consumption in furniture industry is related to the dirt-blast system (38\%), wood processing machines $(27 \%)$ and heating $(10 \%)$. The lighting and the compressor station belong to a share of $7 \%$ therefore they are considered as less energy consumers [4]. 
Often, energy costs in these companies are seen as a fixed overhead, although it is actually one of the costs most easily managed and whose reduction can significantly increase their productivity. A recent study [5] has showed that this industry can reduce energy costs by up to $20 \%$ with relatively small investments and short payback periods. Energy savings are possible in following systems:10 - 15\% in dirt-blast system, 20 to $25 \%$ in lighting system, 10 to $20 \%$ in compressors and heating system from 10 to $40 \%$ [6].

The KERN Schreinerei \& Innenausbau furniture company has achieved a 34,5\% reduction in energy consumption and $19,5 \% \mathrm{CO}_{2}$ emissions by replacing an existing boiler with a new boiler of higher efficiency. Investments in this improvement measure amounted to $60.000 €$ with a 15 -year payback period [7]. Furniture factory in Germany, with the installation of a LED panel, achieved annual savings of $500 €$, with a reduction in electricity consumption of 2.500 $\mathrm{kWh} /$ year and $1,4 \mathrm{t} \mathrm{CO}_{2}$ /year with a payback period of 2 years [8].

With the aim of determining the potential for energy savings, energy related cost savings and related reduction of environment impacts, preliminary assessment of resource efficiency and cleaner production (RECP) has been performed in this company within a framework of the UNIDO National Cleaner Production Program in Bosnia and Hercegovina. The RECP audit has addressed three production plants of the company: plant with sawmills and kilns, furniture manufacturing facility and a plant for the pellets manufacturing facility. The sawmills and kilns plant is located approx. 3 $\mathrm{km}$ far from the furniture manufacturing facility. Total number of employees is 109 . The results of preliminary audit showed potential for improvement of resource efficiency in all of three facilities [9], however the company management decided to select furniture manufacturing facility for detailed analyses. The furniture manufacturing facility consists of three different production lines: manufacture of piece furniture, production of plate and production of taped furniture. Auxiliary systems in furniture manufacturing facility are: boiler room, dirt-blast system and compressor station. First stage of energy audit was focused on analysing energy consumption of furniture manufacturing facility as well as detection of causes of excessed energy consumption. Based on the collected data, and measurement of flue gas composition and measurement taken by the thermal imaging camera an analysis of the energy consumption has been performed. Also, energy indicators relevant to the furniture industry are calculated and compared with similar companies worldwide.

Following measures were selected for a detailed analysis: replacement of the existing boiler, installation of frequency regulators at the engine of the dirt-blast system and introduction of alternative equipment for cleaning instead of the compressed air. The evaluation of the measures from the technical, economic and environmental aspect was carried out.

\section{Energy consumption and energy indicators}

Cost structure analysis has shown that $62 \%$ of energy costs in the plant are related to the furniture manufacturing facility while for plant with sawmills it is $21 \%$ and for pellet production plant it is $17 \%$. Therefore, special attention and focus in the analysis was kept at the furniture manufacturing facility. In Fig. 1. building where production is placed and parts of production lines is shown.
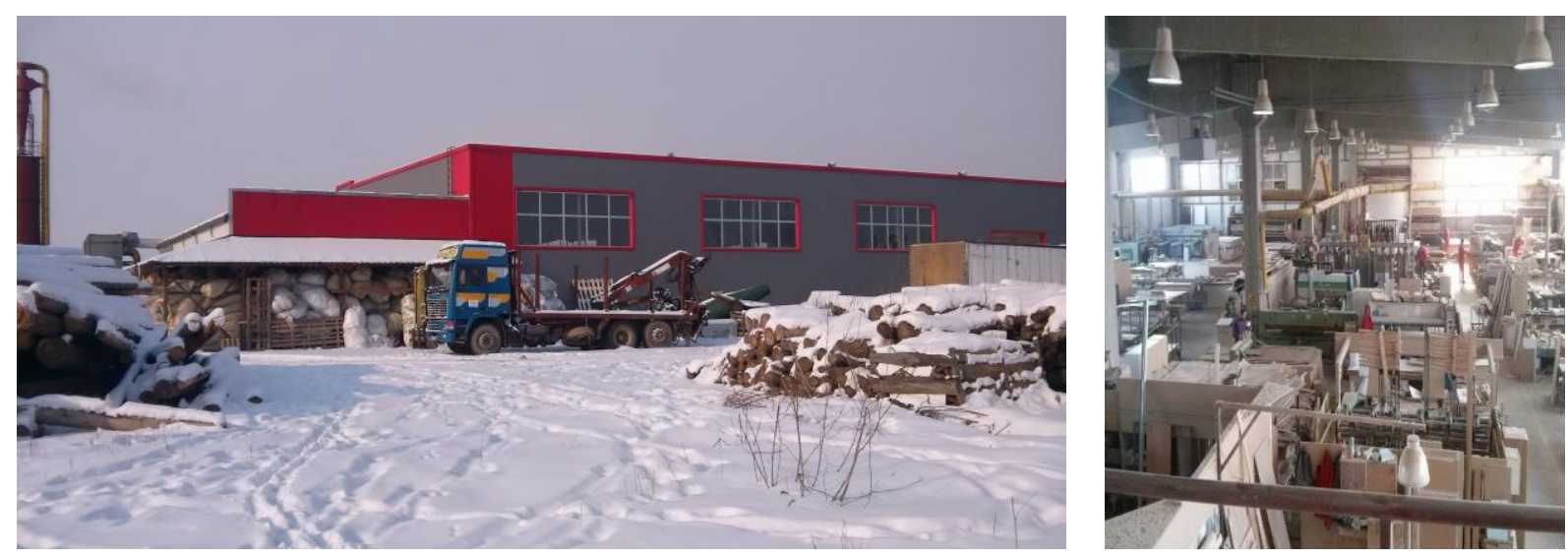

Fig. 1. Production facility building and part of production lines

Installed power of all electrical consumers in the furniture manufacturing facility and their working hours was encountered for calculation and analysis of annual electric energy consumption of all subsystems. Dirt-blast system consumes $71 \%$ of all electrical energy in the facility (Fig. 2.), which is much higher than average [4] and it shows that this system is not efficiently used. The dirt-blast system operates 17 hours a day and with a total engine power of $76 \mathrm{~kW}$. Therefore, it makes the largest share in total electricity costs, followed by the machinery in the production plant (12\%) and compressors $(11 \%)$. Although the machinery in the production plant have large installed engine power their share in total power consumption of the drive is $12 \%$. The reason for this is that the production process is carried out with minimal working hours of machines during the year and a large share of jobs are related to manual carpentry processing. 


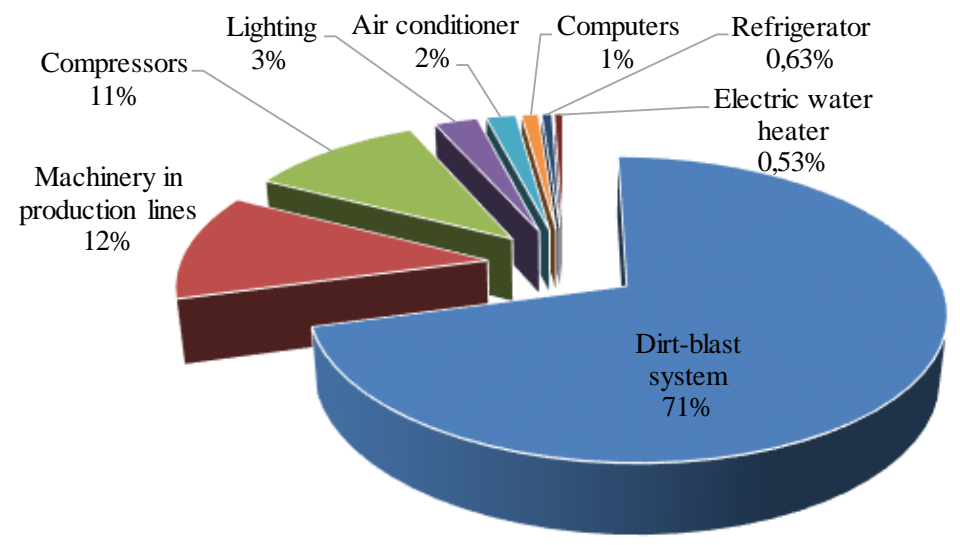

Fig. 2. Structure of electrical energy consumption in production plant

Thermal energy is provided to the facility from the boiler room, located close to the production plant and the dirt-blast system as it is shown in Fig. 3. Inside the boiler room, there is one boiler which serves to heat the water for heating system for administrative part and the production hall. Wood chips generated as a waste during the production process are used as fuel. Since overall efficiency of boiler is low $(41,5 \%)$ due to the poor state of boiler envelope (Fig. 4.) and high losses related to the flue gas, thermal comfort in the heated spaces is not satisfactory. As example, when outdoor temperature was $-15{ }^{\circ} \mathrm{C}$ recorded indoor temperature in production hall was $8{ }^{\circ} \mathrm{C}$. The existing boiler has the power of $700 \mathrm{~kW}$ and low efficiency. Additional load for the heating system is created by the process of dirt-blast when certain air volume is inserted in and extracted from the space. Instalment of any new boiler would not result with economic benefit if the current irregular thermal comfort situation is taken as baseline. Therefore, a hypothetical baseline and corresponding calculation of energy need is taken for scenario with $20^{\circ} \mathrm{C}$ temperature of the office area of and $15{ }^{\circ} \mathrm{C}$ of the production area. The calculated boiler power, with the same boiler efficiency and existing system is $1,13 \mathrm{MW}$, therefore the existing one cannot meet the heat needs of the facility.

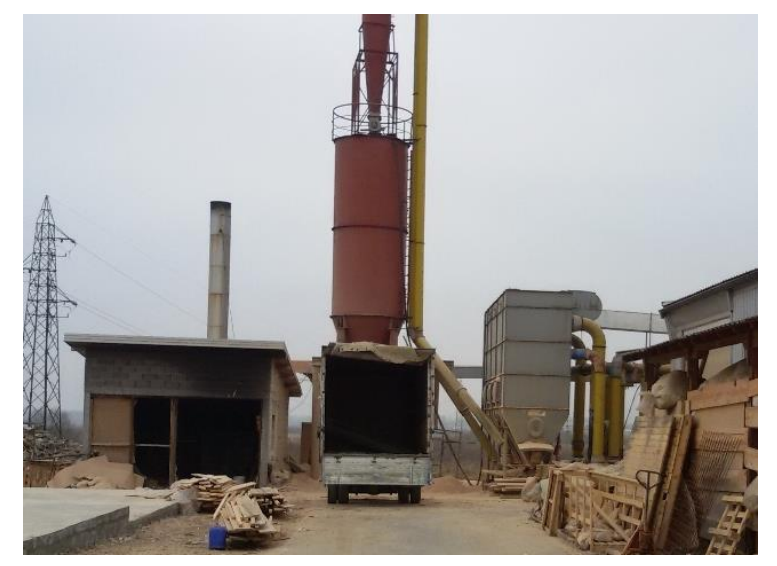

Fig. 3. Location of the boiler room and dirt-blast system

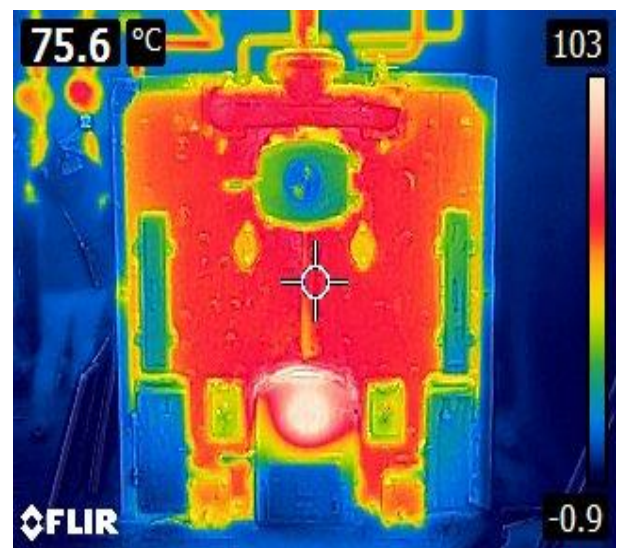

Fig. 4. Thermal image of the boiler

Energy need for heating is highest in the January due to the lowest ambience temperature (Fig. 5.) It is noticeable that energy need for heating of administrative part is smaller than for production hall, due to the smaller heating area off administrative part and high ventilation heat losses in the production hall due to the installed dirt-blast system. Annual energy need for heating for administrative part and production hall is $324.140 \mathrm{kWh} / \mathrm{year}$.

Energy indicators represent a good basis for companies to plan more energy efficient production and allow benchmarking with similar facilities worldwide. Determination and continuous monitoring of indicators ensure detection of irregularities and faster implementation of improvement measures. The Energy and Economy Institute "Energieinstitut der Wirtschaft $\mathrm{GmbH}$ " published research results for 90 furniture manufacturing companies [10]. Within the scope of the research, 7 potential indicators for this type of industry are defined, namely: energy consumed per annual revenues, electricity consumed per square meter work surface, total energy consumed per square meter of work surface, electricity consumed per number of workers, total energy consumed per number of working hours, total energy consumed per cubic meters of treated wood and the ratio of total energy consumed and cubic meter of medium pressure and veneer.

Based on the data provided from the company, five energy indicators are calculated as it is shown in Table 1. 


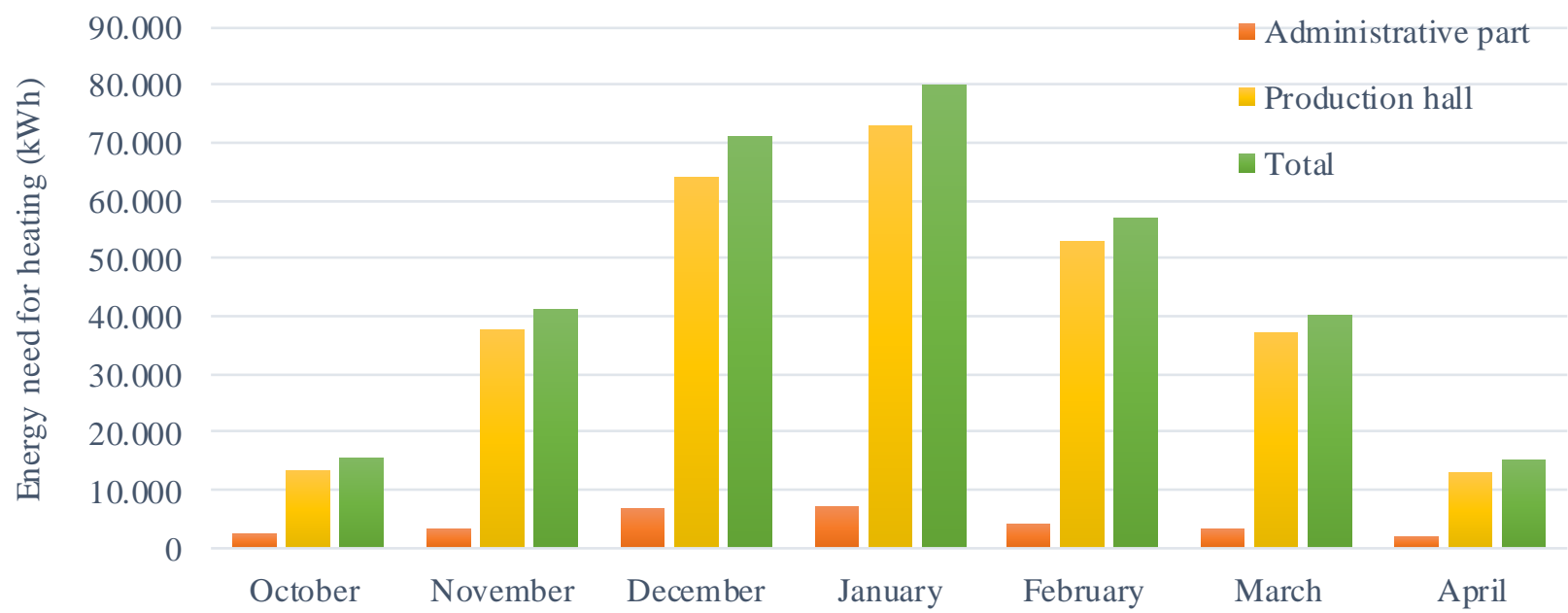

Fig. 5. Energy need for heating for production plant

\begin{tabular}{|c|l|c|}
\hline No. & \multicolumn{1}{|c|}{ Energy indicator } & Calculated value \\
\hline $\mathbf{1 .}$ & Electricity consumed per square meter work surface, $\mathrm{EI}_{1}$ & $180 \mathrm{kWh} / \mathrm{m}^{2}$ \\
\hline $\mathbf{2 .}$ & Total energy consumed per square meter of work surface, $\mathrm{EI}_{2}$ & $551 \mathrm{kWh} / \mathrm{m}^{2}$ \\
\hline $\mathbf{3 .}$ & Total energy consumed per number of working hours, $\mathrm{EI}_{3}$ & $265 \mathrm{kWh} / \mathrm{h}$ \\
\hline $\mathbf{4 .}$ & Electricity consumed per number of workers, $\mathrm{EI}_{4}$ & $6.113 \mathrm{kWh} / \mathrm{no}$. work \\
\hline $\mathbf{5 .}$ & Total energy consumed per cubic meters of treated wood, $\mathrm{EI}_{5}$ & $1.115 \mathrm{kWh} / \mathrm{m}^{3}$ \\
\hline
\end{tabular}

Table 1. Energy indicators of production plant

Fig. 6. shows values of energy indicators for plants whose annual energy consumption exceed $300 \mathrm{MWh}[10]$ and values of the same indicators for considered furniture production plant which consumes annually $410 \mathrm{MWh}$ of electrical energy. Green area represents highest production efficiency and good energy indicators while red area represents lowest energy efficiency.

It is noticeable that only one facility energy indicator $\mathrm{EI}_{5}$ is located in the green area, while others are located in the area which represent low or very low energy efficiency. Low value of $\mathrm{EI}_{5}$ could be explained with high share of manual carpentry processing in the production process. Values of all other indicators $\left(\mathrm{EI}_{1}-\mathrm{EI}_{4}\right)$ revealed that there is a large potential for energy efficiency improvement.

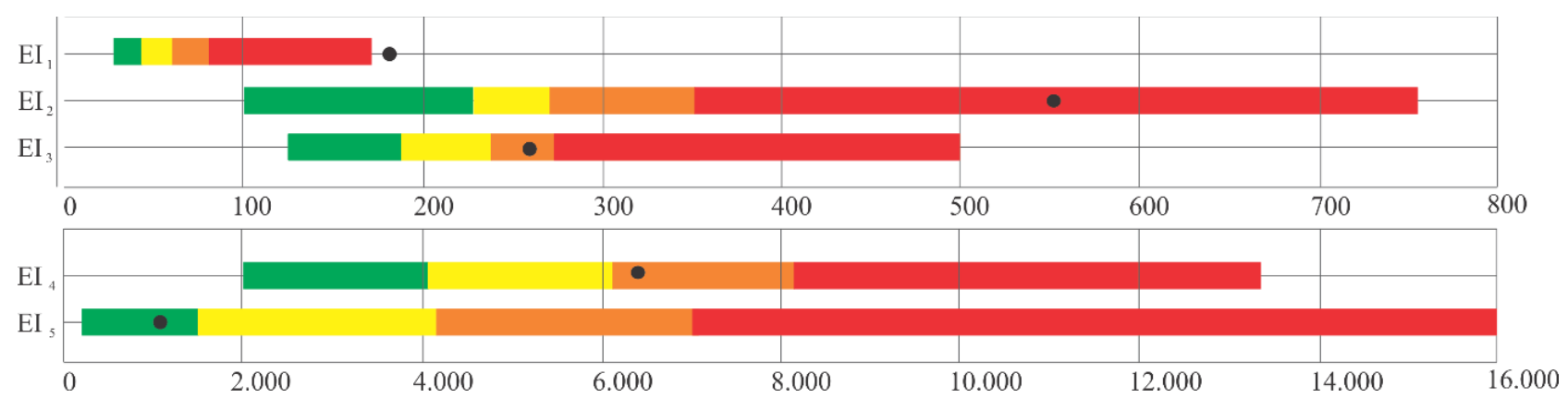

Fig. 6. Energy indicators for considered production plant (black dots) and for similar facilities (coloured bars)

\section{Energy efficiency improvement measures}

After completing a detail analysis of the company energy consumption, three measures are investigated in details: replacement of the existing boiler, installation of frequency regulators at the engine of the dirt-blast system and introduction of alternative equipment for cleaning instead of the compressed air.

Energy savings are calculated as a result of reduction in electricity and heating consumption, while $\mathrm{CO}_{2}$ emission is calculated using the energy savings of energy carrier and related conversion factors. 


\subsection{Replacement of the existing boiler}

Based on the calculated energy need for heating in the facility and a new boiler efficiency of $87 \%$, which is widely available in the market, new boiler power would be $600 \mathrm{~kW}$. Some additional investments should be made, such as new control system and several new fan coils since existing situation is not in line with the actual needs in production hall.

Baseline for the energy ad cost savings is theoretical energy need, boiler power of 1,13 MW and wood chips annual need of $634 \mathrm{~m}^{3}$. Taking into account the available quantities of wood residues arising from production, the company should additionally procure $130 \mathrm{~m}^{3}$ of wood residues at an annual cost of $4.600 €$. New boiler of $600 \mathrm{~kW}$ power and $87 \%$ efficiency for space heating would need $225 \mathrm{~m}^{3}$ of wood chips, which would save $4.600 €$ and also can serve to generate additional earnings from selling the rest of the wood chips which remains from the production process.

Electrical consumption of existing fan coils is not shown in Fig. 2. since they are not in use. This also contributes to the low level of thermal comfort in production hall. Also, baseline for this measure is proper use of existing and new fan coils. Estimated investment for new boiler and 9 fan coils is approx. $45.000 €$. With the total savings of 5.200 $€$, which include savings from the improved control system and boiler efficiency, as well as savings of electric energy, the payback period for the given measure would be 8 years and 7 months.

\subsection{Installation of frequency regulators at the engine of the dirt-blast system}

One of the most important benefit of using frequency regulators is energy savings and resulting electricity cost savings. Speed adjustment of the electric engine offers a number of benefits in terms of productivity increase and reduction of maintenance cost. With full speed control, it is possible to provide a slight acceleration and engine slowdown, avoiding strain and sudden stroke in the machine, while keeping the maintenance costs low and improving the working environment [11]. It is suggested to install frequency controllers on the engines of the dirt-blast system. Estimated investment for three frequency regulators is $9.970 €$ while reduction of electricity consumption will be $20 \%$. As the dirt-blast system contributes with $71 \%$ of the total electricity consumption of the production plant, implementation of this measure will generate annual savings of electricity of $42.354 \mathrm{kWh} /$ year, and $2.600 € /$ year. The payback period is 3 years and 9 months.

\subsection{Replacement of the existing boiler joined with the installation of frequency regulators at the engine of the dirt-blast system}

With installation of frequency regulators on the engines of the dirt-blast system it is reasonable to assume that ventilation losses will reduce up to a $20 \%$. Therefore, calculated boiler power would be a $500 \mathrm{~kW}$. The investment value for a new boiler, 3 frequency regulators and auxiliary equipment is estimated at $50.740 €$. The payback period would be 6 years and 5 months with estimated annual savings of $7.845 €$ /year.

\subsection{Introduction of alternative equipment for cleaning process instead of the compressed air}

In order to calculate energy and cost savings for implementation of electric air blowers as an alternative to compressed air used for the cleaning process, it is necessary to determine the amount and cost of compressed air used in these processes. It includes the consumption of pneumatic tools used for machines, products and clothing cleaning. Taking in to a calculation the compressor power, volume flow rate and pressure of compressor and pneumatic tool, it is calculated that cost related to this activity is $13,15 €$ per month per one pneumatic tool. Electric air blower with power of $600 \mathrm{~W}$ consumes 7,5 $€$ on a monthly basis for 8 hours use in a day. By implementing this measure, energy savings of 8.372 $\mathrm{kWh} /$ year and a decrease of carbon footprint of $12.74 \mathrm{t} / \mathrm{year}$ will be achieved. The value of the required investment is 640 $€$. Taking in to account a number of pneumatic tools (5), annual saving of $339 €$ /year could be achieved. Therefore, the payback period is 1 year and 9 months.

\subsection{Energy and cost savings}

Investment values, annual energy and cost savings with resulting $\mathrm{CO}_{2}$ reduction and simple pay-back period (SPB) for all proposed measures are given in Table 2.

\begin{tabular}{|c|l|c|c|c|c|c|}
\hline No. & Improvement measure & $\begin{array}{c}\text { Investment } \\
(\boldsymbol{€})\end{array}$ & $\begin{array}{c}\text { Energy saving } \\
(\mathbf{k W h} / \mathbf{y e a r})\end{array}$ & $\begin{array}{c}\text { Cost savings } \\
(\boldsymbol{€} / \text { year })\end{array}$ & $\mathbf{S P B}$ & $\begin{array}{c}\mathbf{C O}_{2} \text { reduction } \\
\text { (t/year) }\end{array}$ \\
\hline 1. & $\begin{array}{l}\text { Replacement of the } \\
\text { existing boiler }\end{array}$ & 45.000 & 71.279 & 5.200 & $\begin{array}{c}8 \text { years, } 7 \\
\text { months }\end{array}$ & 8,33 \\
\hline 2. & $\begin{array}{l}\text { Installation of frequency } \\
\text { regulators at the engine of } \\
\text { the dirt-blast system }\end{array}$ & 9.970 & 42.354 & 2.600 & $\begin{array}{c}3 \text { years, } 9 \\
\text { months }\end{array}$ & 64,46 \\
\hline
\end{tabular}




\begin{tabular}{|c|l|c|c|c|c|c|}
\hline No. & Improvement measure & $\begin{array}{c}\text { Investment } \\
(\boldsymbol{\epsilon})\end{array}$ & $\begin{array}{c}\text { Energy saving } \\
(\mathbf{k W h} / \mathbf{y e a r})\end{array}$ & $\begin{array}{c}\text { Cost savings } \\
(€ / \text { year })\end{array}$ & SPB & $\begin{array}{c}\text { CO2 reduction } \\
(\mathbf{t} / \mathbf{y e a r})\end{array}$ \\
\hline $\mathbf{3 .}$ & $\begin{array}{l}\text { Replacement of the } \\
\text { existing boiler and } \\
\text { installation of frequency } \\
\text { regulators at the engine of } \\
\text { the dirt-blast system }\end{array}$ & 50.740 & 1.320 .343 & 7.845 & $\begin{array}{c}6 \text { years, } 6 \\
\text { months }\end{array}$ & 73 \\
\hline 4. & $\begin{array}{l}\text { Introduction of } \\
\text { alternative equipment for } \\
\text { cleaning }\end{array}$ & 640 & 8.372 & 339 & $\begin{array}{c}1 \text { year, } 9 \\
\text { months }\end{array}$ & 12,74 \\
\hline
\end{tabular}

Table 2. Energy and cost savings after applying improvement measures

Replacement of the existing boiler joined with the installation of frequency regulators at the engine of the dirt-blast system contributes to largest proportion of energy savings and $\mathrm{CO}_{2}$ reduction (Table 2.) In general, when applying all three proposed measures, energy savings would be $1.328 .715 \mathrm{kWh} /$ year with related $\mathrm{CO}_{2}$ savings of $85,74 \mathrm{t} / \mathrm{year}$ and simple pay-back period 6 years and 3 months.

After applying all the proposed measures, energy indicators will be reduced (Table 3). In average, they are reduced by the $10 \%$ therefore productivity and facility competitiveness and profit would increase.

\begin{tabular}{|c|l|c|c|}
\hline No. & \multicolumn{1}{|c|}{ Energy indicator } & Current value & Improved value \\
\hline 1. & Electricity consumed per square meter work surface, $\mathrm{EI}_{1}$ & $180 \mathrm{kWh} / \mathrm{m}^{2}$ & $151 \mathrm{kWh} / \mathrm{m}^{2}$ \\
\hline 2. & Total energy consumed per square meter of work surface, $\mathrm{EI}_{2}$ & $551 \mathrm{kWh} / \mathrm{m}^{2}$ & $528 \mathrm{kWh} / \mathrm{m}^{2}$ \\
\hline 3. & Total energy consumed per number of working hours, $\mathrm{EI}_{3}$ & $265 \mathrm{kWh} / \mathrm{h}$ & $254 \mathrm{kWh} / \mathrm{h}$ \\
\hline 4. & Electricity consumed per number of workers, $\mathrm{EI}_{4}$ & $6.113 \mathrm{kWh} / \mathrm{no}$. work & $4.977 \mathrm{kWh} / \mathrm{no}$. Work \\
\hline $\mathbf{5 .}$ & Total energy consumed per cubic meters of treated wood, $\mathrm{EI}_{5}$ & $1.115 \mathrm{kWh} / \mathrm{m}^{3}$ & $1.068 \mathrm{kWh} / \mathrm{m}^{3}$ \\
\hline
\end{tabular}

Table 3. Energy indicators after implementation of improvement measures

\section{Conclusion}

Detail analysis of energy consumption of furniture manufacturing facility has shown that there are systems with exceeded energy use. One of the biggest energy users is dirt-blast system, which contributes to the electrical energy use for $71 \%$, which is much higher than in similar facilities. Reason for this are large installed engines power and long operating time.

Some parameters used for analysis are based on expert assessment, not on measured data. For example, structure of energy consumption of particular systems is calculated based on its installed power and working hours. More accurate results could be delivered by introducing the long-time measurements of electric energy consumption of particular electric energy users. The baseline of a thermal comfort in a production hall is assessed based on a single temperature measurement. More accurate baseline could be determined by long-time temperature measurements in the working area. In order to make accurate energy balance, there is need to register annual consumption of a fuel for the heating system.

Five energy indicators are calculated and compared with similar facilities worldwide. The indicator $\mathrm{EI}_{5}$, total energy consumed per cubic meters of treated wood, indicated high energy efficiency of the company while other four indicated very low efficiency. Having in mind that the $\mathrm{EI}_{5}$ is calculated as consumption of total energy per cubic meters of treated wood, it can not be relevant for companies that beside wood are using wood based board material, have carpentry and have significant proportion of manual work.

Detailed analysis of proposed improvement measures (replacement of the existing boiler, installation of frequency regulators at the engine of the dirt-blast system and introduction of alternative equipment for cleaning instead of the compressed air) has shown that their implementation will provide thermal comfort in production hall and also significant energy savings of $1.328 .715 \mathrm{kWh} /$ year and $\mathrm{CO}_{2}$ savings of $85,74 \mathrm{t} /$ year. After applying all the proposed measures, energy indicators will be improved by $10 \%$.

A particular challenge in the energy efficiency analysis of the wood industry lay in the selection and calculation of a relevant energy efficiency indicators in cases where the industry use a variety of wood raw materials and combines carpentry and manual work. In further research, the focus should be on selecting the appropriate indicators and benchmarking of such companies. The prerequisite for this kind of research is the establishment of a system of energy consumption measurement per production unit, resource and energy management system, in order to obtain a precise material balance. 


\section{References}

[1] G. Granić, at all. (2008). Energy Sector Study in Bosnia and Herzegovina, Ministry of Foreign Trade and Economic Relations Bosnia and Herzegovina

[2] Energy Balances of non-OECD Countries (2014), International Energy Agency

[3] Palcic, I. \& Buchmeister, B. (2016). Energy Efficiency in Slovenian Manufacturing Industry, Chapter 02 in

DAAAM International Scientific Book 2016, pp.011-024, B. Katalinic (Ed.), Published by DAAAM International, ISBN 978-3-902734-09-9, ISSN 1726-9687

[4] Holz, F. \& Schleswig-Holstein, K. (2002). Low-energy operation in carpentry, Hamburg

[5] D. Gordić, M. Babić, V. Šušteršič, D. Končalović, D. Jelić, (2010). Energy Saving Possibilities in the Furniture Industry, Energy / Economy / Ecology, Energy Saver List; Number 2; Academic editions, Belgrade.

[6] http://www.tischler-schreiner.de/energieeffiziente_werkstatt/, Accessed on: 20167-12-27.

[7] Rationalization and Innovation Center (RKW) of the German Economy e. V.RKW Competence Center, http://www.rkw-energieeffizienz.de, Accessed on: 2017-06-19.

[8] Institute for the Environmental Protection (2004), Efficient carpentry, Bavarian State Office for Environmental Protection

[9] Medar, K., Softić, A., Arnaut, S., Midžić-Kutragić, S. Kadrić, Dž., Delalić, N. (2017). Assessment of state and possible improvements resource efficiency in the furniture industry, IEEP, Society of thermal engineers Serbia

[10] Institute of energy GmbH |www.energieinstitut.net | In cooperation with ÖkoBusiness, (2014), Efficient carpentry, Accessed on 2016.12.27

[11] Monomentum automation. Frequency regulators. http://www.momentum-automation.com, Accessed on: 2017-0315. 